\title{
HAYEK/MARX: CONTRA-PUESTOS EN SIMETRÍA. EN TORNO A UN LIBRO DE JORGE VERGARA
}

\author{
Marcos García de la Huerta \\ Universidad de Chile \\ marcos.garciadelahuerta@gmail.com
}

\begin{abstract}
Resumen / Abstract
Este artículo discute algunas ideas centrales del neoliberalismo de Hayek. En su libro Mercado y sociedad. La utopía política de Friedrich Hayek, Jorge Vergara cuestiona el estatus teórico del discurso hayekiano, destacando su carácter utópico. Supera así la recepción corriente, ideológica y económica, de este autor. Este supuesto carácter utópico sugiere una simetría del pensamiento de Hayek con Marx, en tanto ambos comparten un mismo horizonte de comprensión, una misma episteme. La concepción de la razón y del sujeto -una razón producida y un sujeto interactivo igualmente no constituido-, además de la importancia decisiva que ambos le asignan al sistema de mercado, son rasgos destacados de esa copertenencia epistémica. ¿Hasta qué punto dicha simetría puede hacerse extensiva a la política? A este respecto, se plantea una diferencia sustantiva entre Hayek y las utopías del siglo XX.
\end{abstract}

Palabras ClaVE: neoliberalismo, contructivismo, libre mercado, racionalidad, utopía.

\section{HAYEK/MARX: OP-POSED IN SIMETRY. \\ REFLECTIONS ON A JORGE VERGARA'S BOOK}

This paper discusses some of the most central ideas of Hayek's thought. In his book Mercado y sociedad. La utopía politica de Friedrich Hayek, Jorge Vergara questions the theoretical status of Hayek's system of ideas, underlines its utopian nature and in so doing goes beyond the current ideological and economic reception of this author. This supposed utopian character of Hayek's thought discerned by Vergara, suggests certain symmetry with Marx, in as much as both thinkers share the same epistemic outlook. The conception of reason and the subject - a non-constituted reason together with an interacting, non-constituted subject -, and the decisive importance both assign to the market system, are main features of that shared outlook. I question though the extent to which this epistemic symmetry may be projected onto politics. In this respect there is a substantive difference between Hayekian and twentieth century utopian thought.

KEY WORDS: Neoliberalism, constructivism, free market, rationality, utopia. 
$\overline{R A}$ La división del mundo durante gran parte del siglo XX respondía a un antagonismo sobre todo político; había una fundamental simetría y correspondencia entre el capitalismo de Estado y el socialismo de Estado en cuanto al afán de hegemonía y de "crecimiento". El capitalismo existente en la mayoría de las democracias liberales no satisface las exigencias de un liberalismo económico como el de Hayek, pero el socialismo de las "democracias populares" tampoco cumplía las expectativas de Marx referentes a la "extinción" (Verschwindung) del Estado y el advenimiento de la "sociedad sin clases". Una vez que el sistema de economía centralmente planificada fue, por así decirlo, refutado por la historia, la cuestión ya no se plantea dentro de los mismos parámetros. Ese tipo de economía planificada tuvo una rápida obsolescencia tras ser desechada en la URSS y China, y se impuso en la mayor parte del mundo un sistema que combina en diferentes formas el mercado y la regulación estatal. Un "mercado bueno" con un "Estado malo", pues el "Estado bueno" era el que debía desaparecer. "Estado bueno", entonces, ha de traducirse por "Estado subsidiario": el que interviene para crear mercado o vigorizar el existente. En suma: "el bueno" es el mercado y el Estado, por definición, es "malo". ¿Qué fue, entonces, del verdadero "Estado bueno": el que se sobrepone al mercado, se marchita hasta desaparecer y abre unos posibles imposibles? Más allá de esa confrontación entre sistemas políticos diferentes ¿es posible discernir en el plano de los regímenes discursivos una simetría equivalente a aquella?

En su libro Mercado y sociedad. La utopía política de Friedrich Hayek ${ }^{1}$, Jorge Vergara comenta a este autor, uno de los más representativos e influyentes del neoliberalismo. La obra está muy bien documentada y es, sin duda, un aporte a la discusión del pensamiento de Hayek, de sus bases antropológicas, epistemológicas y filosófico-políticas, aspectos por lo general omitidos o relegados, y cuyo "conocimiento, según Vergara, es necesario para comprender el sentido de sus teorías económicas"2. Se propone "analizar la estructura teórica del pensamiento de Hayek, incluyendo no solo los supuestos sino también los principios explícitos de dicha estructura desde una perspectiva hermenéutica", procurando la mayor ecuanimidad y basándose en un cuidadoso examen de sus textos ${ }^{3}$. El título del libro, en todo caso, sugiere que se trata de una utopía.

El neoliberalismo suele pasar por una doctrina económica que conserva la orientación fundamental del liberalismo clásico, hacia un mínimo de intervención estatal; Vergara muestra que lo reformula y modifica en algunos aspectos importantes. Por ejemplo: difiere de los clásicos en cuanto a su antropología, su teoría del valor, su concepto de la libertad, de la igualdad y de la racionalidad económica ${ }^{4}$. Respecto de esta última, Hayek estima que no es un atributo que todos los hombres posean en virtud de su naturaleza, sino que es privativa de una minoría, en tanto la gran mayoría se conduce

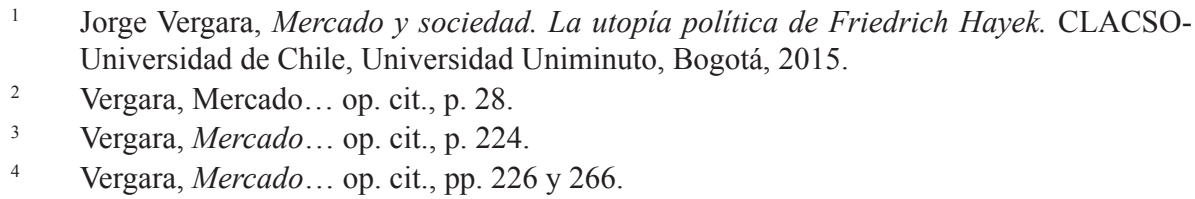


en escasa medida según el canon de los individuos posesivos que maximizan la utilidad. El propio Mises, maestro de Hayek, sostiene que hay una ruptura con el liberalismo clásico: "este modo de entender el liberalismo implica un "nuevo programa político"": "el mundo [nunca] llegó a conocer una verdadera era liberal, pues jamás permitió al liberalismo funcionar en su plenitud"s. Esto avalaría el carácter utópico. Pero cabría preguntar si algún sistema social llegó alguna vez a "funcionar en plenitud", y si lo que Mises y Hayek afirman respecto del neoliberalismo no es también válido para cualquier sistema. Afirmar, por ejemplo, que el mundo ya conoció una era verdaderamente socialista suena, a estas alturas, como una condena. Subsiste, entonces, la cuestión acerca del estatus epistemológico del neoliberalismo: ¿Es una teoría, como pretende Hayek, una ideología, una idea reguladora en sentido kantiano, una "visión del mundo" o una utopía? ¿O tal vez una combinación de algunas o todas estas alternativas? Vergara responde: "este pensamiento no es propiamente una teoría científica antropológica y social, ni tampoco una antropología y filosofía política. Más bien sería un discurso análogo al teológico político, de carácter economicista y que constituye una utopía política". Más adelante agrega: "Que Hayek sea un economista profesional que ha desarrollado teorías científicas importantes y a la vez un teórico del derecho y la política, nos haría pensar que sus concepciones constituyen una gran teoría social. Sin embargo, este no es el primer caso en que un destacado científico traspasa los límites del discurso racional y se compromete en la construcción de una 'visión de mundo', incorporando a sus discursos científicos sus convicciones teológicas o metafísicas"7.

“¿Traspasa (Hayek) los límites del discurso racional?”

Intentaré mostrar que es posible leer a Hayek como el anti-Marx, una suerte de antídoto del hegelianismo. Eso implica descartar de plano las lecturas solo "científicas", que limitan la discusión, pues entienden la razón como algo ya constituido y, por lo mismo, sin interés científico: la racionalidad como tal no es problema para la ciencia. Hayek, en cambio, entiende la razón como algo que se ha producido históricamente y continúa produciéndose, a través de la corrección y perfeccionamiento de las instituciones, las leyes, las costumbres, las ideas y el conocimiento. Él mismo entiende su obra como parte de un proceso de restablecimiento de la racionalidad liberal amenazada, según él, por una tendencia al colectivismo y al "socialismo". Está lejos de ser un "economista puro". Si lo fuera, seguramente no estaríamos comentándolo y discutiendo con él. Nos interesa, desde luego, por la relevancia que ha adquirido el neoliberalismo en el mundo; la "globalización" actual es en gran medida de cuño y letra neoliberal. Hayek es la casa matriz de este pensamiento, algo semejante a lo que Marx ha sido para las izquierdas: la nave insignia. Esto implica excluir también las "lecturas internas" ceñidas solo a la letra. A menudo ocurre que mientras más influyente es un autor, más difícilmente se deja apresar en la gavilla del economista "puro". Con Marx ocurre algo parecido:

Mises, Liberalism, Irvington, New York, 1985.

Vergara, Mercado... op. cit., p. 243.

Vergara, Mercado... op. cit., p. 256. 
muchas veces se le "refuta" aduciendo que tal o cual teoría suya -la del valor-trabajo o de la plusvalía-, son erróneas o insuficientes; o bien, señalando que sus predicciones resultaron fallidas. Los filósofos suelen invocar motivos similares: lo descalifican por no pertenecer al gremio: "Marx no es filósofo". Claro que no, si eso significa ser filósofo profesional.

Vergara está lejos, sin embargo, de ese cientificismo. Señala, precisamente, que las bases antropológicas, epistemológicas y filosófico-políticas son aspectos generalmente omitidos del pensamiento de Hayek, cuyo "conocimiento es necesario para comprender sus teorías económicas". Uno de los méritos de su libro, y no el menor, consiste, justamente, en abrir la discusión con un excomulgado de la academia, al menos, del gremio de los filósofos profesionales. Lo han ignorado por ignorancia, si se me permite la redundancia, porque lo consideran solo un economista. Es una descalificación gratuita, si se considera que las ideas neoliberales en ninguna parte recibieron una acogida tan obsecuente y una puesta en práctica tan obstinada, como en esta región y particularmente en Chile. Los filósofos profesionales, a menudo carentes de cultura económica, prefirieron descartarlo sumariamente, quizá porque lo asocian con la dictadura. Eso tenía la ventaja, en todo caso, de evitarse el trabajo de leerlo. No es extraño, entonces, que la recepción de Hayek haya quedado entre nosotros en manos de economistas o bien adquiriera un cariz econofóbico.

El siguiente pasaje de Vergara es ilustrativo de esta diferente lectura: "La sociedad de relaciones mercantiles desarrolladas... fue el resultado de un proyecto político que se impuso mediante la coerción y la persuasión. Fue capaz de elaborar un nuevo saber, una nueva racionalidad secular, y crear el gran mito del progreso permanente... El pensamiento de Hayek es la última gran expresión [de ese] proyecto intelectual y político que empezó a ser elaborado en el siglo XVII, adquirió el carácter de una filosofía mecanicista con Hobbes, de democracia de mercado con Locke y se convirtió en un gran proyecto económico con Smith, Ferguson y Mandeville"9.

Solo cabría agregar que, al concebir el proceso de formación de la "sociedad mercantil desarrollada", como "un proyecto", se supone sería obra de uno o varios proyectistas, es decir, el sistema de mercado habría sido ideado o planificado, al modo de los inventos. Es cierto que las "sociedades de mercado", o como quiera se les llame, no resultaron de un proceso del todo anónimo, como las precedentes. El feudalismo, por ejemplo, no tuvo sus Hobbes, sus Locke o sus Smith. La tradición de pensamiento liberal es una excepción al respecto, porque ha sido un sostén formidable del sistema de mercado, que tendría artífices con nombre propio. El sistema de mercado mismo se instauró, como ha mostrado Karl Polanyi y nos recuerda Vergara, a través de múltiples y sucesivas intervenciones creadoras de mercado; no nació espontáneamente sino que el Estado ha sido su gran impulsor, promotor y sostenedor. De ahí a concluir que la sociedad se construye o se inventa, hay solo un paso, pero lo cierto es que gran

\footnotetext{
Vergara, Mercado..., op. cit. p. 28.

Vergara, Mercado..., op. cit., p. 268.
} 
parte de los avances que hicieron posible la civilización actual fueron indeliberados y anónimos. La agricultura, el comercio, la navegación, las ciudades, la democracia misma y el Estado no tienen inventores conocidos y rebasan la previsión de los actores. La Ilustración creó la "mística del progreso", sí, pero junto con ella nació la mística del sujeto y la mística del invento: inventó al inventor. La utopía moderna ¿no nació de la extensión de la lógica del invento a las transformaciones de la sociedad?

El fenómeno quizá más característico y definitorio del siglo XVIII fue la progresiva limitación del poder de los Estados absolutos. El liberalismo económico clásico, por una parte, y la revolución republicana por otra, son en este aspecto fenómenos paralelos; ambos establecieron ciertos principios que limitaron el poder de las monarquías. El descubrimiento de una lógica de funcionamiento del sistema económico puso de relieve ciertas reglas de la economía que los gobiernos no pueden dejar de tener en cuenta, y harían bien en no ignorar. Este fenómeno de limitación de la razón de Estado desborda la acción de sujetos determinados; se produjo en diferentes sitios, de distintas maneras, con actores múltiples, muchas veces por simple emulación y siguiendo estrategias diversas. Vista en retrospectiva, la formación de las sociedades de mercado aparece asociada a unos nombres propios, que de algún modo contribuyeron a desarrollarlas y legitimarlas, sobre todo en Europa, y al comienzo. "Proyectar" significa saber lo que uno se propone antes de realizarlo; un proceso que se extiende a lo largo de un siglo o más, no es posible definirlo de antemano. Hacer extensiva a los clásicos la intención política que domina en algunos autores, incluso en algunas obras del mismo Hayek, supone una historia escrita en futuro anterior, una cuyos actores hacen la historia y saben lo que hacen antes de llevarlo a cabo. El carácter indeliberado, contingente, de los sistemas sociales es una idea central en Hayek, un resuelto adversario de la ingeniería política, aunque él no siempre sea consistente en este punto. Una de las principales críticas a las políticas neoliberales aplicadas en Chile ha sido, precisamente, que se han llevado a cabo haciendo tabla rasa de su historia, dando la espalda a su configuración como sociedad. Lo que Mario Góngora llamó “planificaciones globales” son, justamente, los intentos de reconfigurar el colectivo "partiendo de cero", como si carecieran de todo espesor histórico ${ }^{10}$. Si Hayek rechaza los intentos de rediseñar la sociedad siguiendo un ideal racional -el "constructivismo", como él lo llama-, no puede hacer valer ese rechazo discrecionalmente solo para la "construcción" del socialismo. En cambio, es consistente cuando invoca el juicio de Cicerón, señalando la ventaja de la constitución romana, porque fue resultado del esfuerzo de muchas generaciones, y no de un solo sujeto. Volveremos sobre este punto.

En el capítulo 7, Vergara compara a Hayek con Marx, con Habermas y con Heidegger. Con quien Hayek polemiza y dialoga es sobre todo con el socialismo e implícitamente, con Marx, no tanto con Habermas y mucho menos con Heidegger, de modo que la confrontación más directa y pertinente es con aquel. A pesar de la

10 Mario Góngora, Ensayo sobre la noción de Estado en Chile en los siglos XIX y XX. Universitaria, Santiago, 1981. 
contraposición evidente y radical con el marxismo, hay una homología entre Hayek y Marx. Comparten, desde luego, la intención política de su discurso, lo que Marx llamó la "terrenalidad" del pensamiento: su capacidad de incidir en la contingencia. La importancia concedida al funcionamiento del sistema de mercado -el "capitalismo"-, les aproxima en cuanto a su copertenencia a un mismo horizonte de comprensión, una misma episteme, diría Foucault, quien nunca vaciló, por lo demás, en incluir a Marx entre los economistas clásicos. Eso se traduce en una suerte de ontología del mercado, en un caso y, en el otro, en una filosofía de la historia determinada, "en última instancia", por la economía. Ambos se distancian, no obstante, del economicismo corriente; Hayek rechaza expresamente la política de los expertos y su corolario, la tecnocracia. Marx, por su parte, jamás imaginó que la desaparición o "extinción del Estado" anunciada por él, quedaría indefinidamente entrampada debido a la formación de una nueva "clase" burocrática que prospera a la sombra del "Estado proletario", convirtiéndose en su más seguro sostenedor. Subestimó, en buenas cuentas, el peso propio del Estado y las dificultades que plantea a la "construcción del socialismo".

El hecho de que Hayek piense de cara al acontecimiento abre, sin embargo, un profundo abismo temporal y fáctico con Marx. Él y Mises -en general la Escuela de Mont-Pelerin- responden a una época de intensa confrontación ideológica y política. Su resuelta defensa del sistema de mercado está sin duda poderosamente influida por el ascenso de los totalitarismos y el antagonismo fundamental entre capitalismo y socialismo, agudizado tras el término de la Segunda Guerra. El "enemigo" principal pasó a ser el "socialismo", y la confrontación con el marxismo adquirió un significado crucial. Para Hayek, en todo caso, el dirigismo estatal en cualquiera de sus formas, y en particular el Estado de bienestar, representa una deriva totalitaria, un "camino de servidumbre", en tanto conduce a la dependencia del individuo del Estado. Los dos totalitarismos clásicos se autodefinían, por lo demás, como "socialistas": el nazi como nacional-socialista y el estalinista como proletario o internacionalista. A ambos se les considera "utopías", de modo que el título -La utopía política de Friedrich Hayek" (Vergara), es provocativo, porque a Hayek se le considera un teórico y, para el neoliberalismo en general, las utopías del siglo XX representan, precisamente, la mayor amenaza a la libertad: son el enemigo a combatir. En el orden económico, el neoliberalismo surgió como réplica a la orientación keynesiana predominante tras la gran crisis de los treinta, enfatizando, contra el intervencionismo keynesiano, las virtudes de la competencia y del automatismo mercantil. No deja de ser sorprendente, en todo caso, que Hayek quisiera terminar con el Estado social, al que le achacaba obstaculizar el dinamismo de los mercados. Lo cierto es que, lejos de haber sido un "camino de servidumbre", dicho Estado cumplió una doble función contra-cíclica y neutralizadora del conflicto político.

El nombre de utopía (u-topos, lugar ninguno) viene del libro de Tomás Moro, pero las utopías renacentistas de Bacon, Campanella y del propio Moro no tienen mucho que ver con las llamadas utopías del siglo XX; aquellas también poseen el carácter ficcional, desiderativo, que caracteriza a todas las utopías, pero aquellas establecen una distancia irónica con el mundo que describen, una "realidad" fruto de la fantasía, un juego de la imaginación. En el libro de Moro, el no-lugar (u-topos) es una isla 
imaginaria que no figura siquiera en los mapas. Ninguna de las utopías renacentistas intentó rehacer el orden del mundo ni concitó la adhesión de millones ni tuvo, como las religiones reveladas, sus profetas y mártires.

Lo que procura a las utopías del siglo pasado su poder transformador y su carácter amenazante, es la asociación del deseo con los ideales de la razón. Este vínculo se da también en las ideologías, que más de alguna similitud tienen con las utopías; se diferencian de éstas, desde luego, en que se expresan o tienden a traducirse en la política. La ideología, entendida como "falsa conciencia", implica un engaño o divergencia entre la llamada realidad social y un reconocimiento erróneo de ella. Esta "conciencia deformada" sería susceptible de un tratamiento que la lleve al des-engaño, a reconocer su error y salir del engaño. En una versión más elaborada, se concibe la ideología no solo como "conciencia falsa" de una realidad constituida, sino como engaño constituyente de ésta. La ideología no se desvanece enfrentada a un estado de cosas, porque la distorsión está inscrita en su misma esencia. Es decir: la ideología sostiene la fantasía que regula la realidad social: $\sin$ falsa conciencia algo no funciona en "la realidad" y es ésta la que "se desvanece" o pasa a ser una realidad distinta ${ }^{11}$. Alguien que cree ser lo que no es, no solo tiene una falsa conciencia de sí, pues en tal caso bastaría un "tratamiento" que disipara su ilusión y produjera su "mejoría". Pero si el creer ser define su identidad imaginaria, es la totalidad de su condición la que se destruye con su mejoría. La ideología, entonces, es continente de la conciencia y no solo un contenido suyo; no basta confrontar una ideología con una verdad para disiparla, como ocurre con la "falsa conciencia" que, en principio, reconoce su error enfrentada a aquello que la falsea. No es así, si "la falsedad" legitima un modo de ser. En La voluntad de poder, Nietzsche apuntaba a este carácter constituyente de la ideología cuando señalaba: "La verdad es una modalidad de error sin el cual una especie determinada de ser viviente no podría existir" 12 . La relación con la "verdad" es constitutiva, aunque sea en la forma del error.

El neoliberalismo tiene cierto "aire de familia" con las ideologías del siglo XX (con las utopías, diría Vergara). Hayek mismo rechaza la posibilidad de diseñar la sociedad conforme a ideas o planes. Recordemos que Marx se negaba a definir cómo sería la futura sociedad socialista; apunta con eso en una dirección análoga, porque la crítica de un determinado estado de cosas es algo muy distinto a la creación de un orden nuevo. Éste no puede definirse de antemano ni ser instaurado a voluntad: no es resultado de un diseño. Concebir el acontecimiento como fruto de "un proceso histórico-natural" (Marx), es una cosa, y otra distinta es querer construir la sociedad conforme a un plan o modelo. Marx desarrolló una concepción de la historia mucho más consistente en este aspecto que su concepto del Estado y la política; subordinó la política a la historia, a una necesidad histórica. Las "democracias populares" recurrieron a esa supuesta

\footnotetext{
11 Adorno y Horckheimer, Dialéctica de la Ilustración, Trotta, Madrid, 2005. "La industria cultural".

12 La voluntad de poder. Libro Tercero, 1, 268.
} 
necesidad histórica para legitimarse y avalar la "construcción del socialismo". Aunque Marx renuncia expresamente a señalar cómo se realizaría dicha "construcción" y su obra teórica no es asimilable a la ideología de combate en que se convirtió el marxismo en el "socialismo real", su nombre quedó asociado a aquella. Los resultados de esa asimilación, comparados con las "aplicaciones" del neoliberalismo, son de otro orden y magnitud, sin duda, pero lo que hace pertinente la comparación es la distancia que separa la teoría y su realización en ambos casos. Hayek tiene la ventaja, si así puede llamarse, de haber comprobado los efectos de algunas de sus ideas. Aprobó expresamente las políticas económicas de las dictaduras, en especial la argentina y la chilena, aduciendo que la ausencia de costumbres y tradiciones libremercadistas las hacía aconsejables, a pesar de contravenir flagrantemente dos aspectos fundamentales de su pensamiento: su persistente rechazo de la ingeniería política -el "constructivismo"-, como él la llama-, y desde luego, la competencia misma.

El socialismo, entendido como un modelo de sociedad "construida" conforme a reglas y pautas determinadas por la razón sería, para Hayek, una utopía. Dentro de esta acepción caben, desde luego y en primer lugar, los sistemas de economía centralmente planificada, los llamados "socialismos reales" o "socialismos de Estado". Hayek contrapone a ellos un sistema de mercado desregulado que supone competencia, transparencia y movilidad perfectas, es decir, la posibilidad de cada uno de los actores de conocer todos los precios, de poder transar y producir lo que más le convenga en el lugar y en el momento más adecuado. Este sistema nunca ha existido y nunca existirá, porque la competencia se perfecciona ahogando la competencia, es decir, concentrando. Hayek incurre pues en la misma falacia habitual en la crítica a los sistemas de mercado, a los que se les confronta con una idea que "corrige" sus distorsiones y desequilibrios. Como la comparación tiene lugar solo en la imaginación, la prueba juega a favor de la idea, pues "la realidad es siempre más limitada que la idea que sirve de modelo a su producción" 13 .

El calificativo de utopía para el neoliberalismo podría sustentarse en esa hipótesis de un mercado ideal, que desautoriza las intervenciones. El sistema de precios contendría sus propios correctivos y la intromisión de la autoridad sería innecesaria y contraproducente, pues los efectos del correctivo serían peores que la corrección. Los mundos de recambio son, por definición, peores que el original: ignoran o enmascaran los efectos indeseados de la alternativa propuesta. El actual no es "el mejor de los mundos posibles", requiere de enmiendas, pero es el mismo mundo que necesita reformas; hay una fundamental homología y continuidad entre lo imaginado y lo existente. No ocurre lo mismo con el comunismo, que supone un mundo y una humanidad diferentes a las actualmente existentes; incluso si se concibe como una hipótesis (Badiou), me parece que el comunismo es un ente de razón, una utopía. El libre mercado no implica un mundo distinto, tampoco es un principio regulador en sentido kantiano. La "utopía" de Hayek sería, entonces, muy singular, porque pretende un isomorfismo fundamental con el 
funcionamiento del mercado. En este aspecto, el neoliberalismo conserva la orientación del liberalismo clásico hacia un Estado mínimo y la enmienda de la política. El "Fin de la historia" (Fukuyama) no dice otra cosa: ha habido historia pero ya no la hay; vale decir, el inmovilismo está en marcha, ya nada podrá detenerlo. Lo cierto es que el capitalismo lleva tres siglos renovándose y esa historia de reinvenciones presumiblemente continuará, sin rumbo predecible. Pero la misma dificultad/ imposibilidad de acabar con el capitalismo, genera un modo de pensar que consiste en hacer como si éste no existiera. No basta, en todo caso, la predicción fallida para calificar una utopía, porque la teoría también procede abstrayendo, suponiendo condiciones ideales.

Hayek insiste más en la necesidad de la competencia que en la desregulación misma. "Es importante no confundir la oposición contra la planificación con una dogmática actitud de laissez faire, escribe. "La argumentación liberal se basa en la convicción de que allí donde pueda crearse una competencia efectiva, ésta es la mejor guía para conducir los esfuerzos individuales" ${ }^{14}$. Cuando está en juego la salud de la población, no solo es recomendable sino obligada la intervención: "Prohibir el uso de ciertas sustancias venenosas o exigir especiales precauciones para su uso, limitar las horas de trabajo o imponer ciertas disposiciones sanitarias es plenamente compatible con el mantenimiento de la competencia" ${ }^{15}$. Otro tanto vale para los servicios públicos: "Tampoco son incompatibles el mantenimiento de la competencia y un extenso sistema de servicios sociales, en tanto que la organización de estos servicios no se dirija a hacer inefectiva en campos extensos la competencia"16. En fin: "El funcionamiento de la competencia no solo exige una adecuada organización de ciertas instituciones como el dinero, los mercados y los canales de información -algunas de las cuales nunca pueden ser provistas adecuadamente por la empresa privada-, sino que dependen, sobre todo, de un sistema legal apropiado, de un sistema legal dirigido, a la vez, a preservar la competencia y a lograr que ésta opere de la manera más beneficiosa posible"17. Conclusión: "En ningún sistema que pueda ser defendido racionalmente el Estado carecerá de todo quehacer" ${ }^{\prime 18}$.

Estas aclaraciones fortalecen su argumentación. Mientras funciona la competencia, la ganancia puede mantenerse dentro de márgenes reducidos; si hay concentración monopólica, en cambio, mejora la ganancia pero a expensas de eventuales ineficiencias y mayores abusos. En un mercado acotado, local o nacionalmente, es posible que opere el principio de la competencia con mínima vigilancia de la autoridad. Pero es muy difícil, si no imposible, que la sola competencia mercantil pueda crear o alterar una hegemonía; ocurre más bien al revés: dada una hegemonía, ésta permita operar libremente al mercado, hasta el punto que llegue a constituir una amenaza para la hegemonía, y entonces la competencia será entorpecida y boicoteada hasta ser sofocada.

$14 \quad$ Friedrich von Hayek, Camino de servidumbre. Alianza Editorial, Madrid, 1985, p. 64.

15 Hayek, Camino...op. cit., p. 66.

16 Hayek, Camino...op. cit., p. 66.

17 Hayek, Camino...op. cit., p. 66.

18 Hayek, Camino...op. cit., p. 68. 
Es la hegemonía la que en definitiva impone las reglas; el mercado nunca opera en el tubo de ensayo del imaginario, siempre lo hace en un campo de fuerzas, en un marco de relaciones políticas. La libre competencia, que debiera favorecer a las naciones menos poderosas, funciona bajo la tutela de una hegemonía, discrecionalmente. Si el mercado hace peligrar una posición hegemónica, los Estados más poderosos imponen tratados o recurren directamente a la fuerza. Junto con idealizar el mercado, el neoliberalismo sublima el poder, es decir, reduce las relaciones de poder a "competencia mercantil", y concibe el intercambio solo en su aspecto monetario, cuantitativo.

Vergara afirma que "la concepción del hombre de Hayek fue elaborada... y desarrollada paralelamente, y en directa relación con su teoría de la sociedad y del mercado"19. Este es un punto fuerte, porque implica que la sociedad existente -"de relaciones mercantiles desarrolladas"-, concuerda con ciertas tendencias espontáneas de los hombres. Se solía llamar "naturales" a dichas tendencias; por lo menos, son muy generalizadas. La libertad es una de ellas, en tanto es el individuo singular el sujeto libre; no habría propiamente sociedades libres, un término doblemente metafórico, según Hayek: "la sociedad" sería una abstracción, son los individuos actuando en su propio beneficio, los verdaderos titulares de la libertad. La idea de sociedad "presupone o implica la colectiva persecución de unos objetivos compartidos que normalmente solo pueden lograrse a través de una colaboración consciente" ${ }^{20}$. Eso solo se da en "sociedades" restringidas: familias, grupos y tribus. Como en las sociedades complejas no hay tales objetivos compartidos, la idea misma de sociedad comporta abstracción y conlleva una tendencia al despotismo. Hayek "rechaza cualquier teoría social colectivista que considere los conjuntos sociales como entidades en sí mismas, cuya existencia sería independiente de los individuos" ${ }^{21}$. Rebate, no obstante, lo que llama "falso individualismo", precisamente porque el "verdadero" sería "primordialmente una teoría de la sociedad, un intento por conocer las fuerzas que determinan la vida social del hombre" ${ }^{22}$. Intenta así rectificar el atomismo que suele atribuirse al liberalismo, el supuesto de "individuos aislados y autónomos, en lugar de entender que el carácter y la naturaleza de los hombres están determinados por su existencia en la sociedad”. Afirmación sorprendente, que corresponde con lo expresado por Marx en las Tesis, donde impugna a Feuerbach, el concebir un "individuo abstracto", separado del "conjunto de relaciones sociales" que lo constituyen. La realidad humana es producida a través de dichas relaciones; el hombre en singular es "una abstracción" (Tesis VI). Un hombre nuevo, no sujeto a la necesidad económica, como lo imaginó Marx, aunque no use esa expresión, se contrapone radicalmente con la antropología de Hayek, pues supone la superación del egoísmo y la escasez. En este sentido, la idea de comunismo es contraria a toda antropología. Y la pregunta por la esencia del hombre es descaminada, porque supone una realidad constituida e independiente: "abstracta" (Tesis VII y VIII). La idea

19 Vergara, Mercado..., op. cit., p. 56.

20 Hayek, La fatal arrogancia. Centro de Estudios Públicos, Santiago, 1991, pp. 181-182.

$21 \quad$ Vergara, Mercado...op. cit., p. 64.

22 Hayek, Individualismo. El verdadero y el falso. Revista Estudios Públicos n ${ }^{\circ} 22$. 
de un "hombre nuevo", adecuado a un futuro más perfecto, es una criatura de razón. Las sociedades complejas siempre contienen división del trabajo, jerarquías, estratos o "clases" y, por tanto, Estado. La hipótesis comunista en su forma original, se inspira en las sociedades arcaicas y se asocia con la extinción del Estado, un fenómeno jamás producido en sociedades complejas. La idea de una sociedad comunista responde también a un modelo societario sin división del trabajo y sin Estado. Los "socialismos reales" no pueden perdurar sin reforzar y extender el poder del Estado. El esfuerzo más serio llevado a cabo hasta ahora para encaminar un Estado hacia el comunismo fue la Revolución cultural de Mao: una revolución dentro de un Estado socialista, que logró exactamente lo contrario de lo que se proponía: el desarrollo del capitalismo en China. Ironía de la historia o argucia de la razón, el caso es que el "comunismo real" resultó la vía más expedita hacia la instauración de relaciones de producción capitalistas. Ese formidable efecto de culatazo de la "revolución cultural" mostró que, si es difícil el triunfo de una revolución, mucho más lo es el triunfo sobre su contrarrevolución. Un Estado comunista, por lo demás, es una contradicción en los términos, como fuego helado o círculo cuadrado.

Hayek intenta abordar el fenómeno económico en la perspectiva de los propios agentes; sobreentiende los móviles egoístas sin sublimarlos ni teorizar sobre ellos. Parte de la base de que las conductas individuales son espontáneamente "individualistas". En el Prefacio de El capital, Marx advierte que si allí no aparece "la figura del capitalista pintada con tonos color de rosa" es porque "las personas (representan) la personificación de categorías económicas", o sea, que la lógica de los agentes se asimila a la del sistema ${ }^{23}$. Eso responde al mismo propósito de aproximarse al punto de vista de los actores, sin imponerles cánones ajenos a su conducta. Sin embargo, la competencia supone asociación, acción concertada y pugnas de poder. Según Hayek, "solo metafóricamente puede llamarse 'lucha' la competencia" 24 . Sin embargo, muchas veces resulta ventajoso renunciar a la ganancia, incluso soportar pérdidas temporalmente, con tal de eliminar a un competidor. La más segura ganancia viene de ganar una posición de poder. La competencia es lucha sublimada, incluso guerra sublimada, a veces nada sublime. Hayek en esto tiene el mismo punto ciego de los clásicos: en las relaciones mercantiles parece no ver que está en juego el poder.

La difundida creencia según la cual 'siempre es mejor cooperar que competir' se sostiene en la confianza de que puede haber un acuerdo fundamental en cuanto a los fines y los medios a emplear, pero semejante consenso sería imposible en las sociedades complejas. "La cooperación, al igual que la solidaridad, solo son posibles si existe un

23 El a-humanismo de Hayek tiene una réplica en el a-humanismo de El Capital. Hayek "rechaza los valores de la igualdad, la fraternidad y los derechos humanos en su integridad" (Vergara, op. cit., p. 138). Marx tampoco está por la igualdad ni por la redistribución de la riqueza; su teoría social es eminentemente política. Ni uno ni otro cede a la ilusión de un capitalismo con rostro humano. 
amplio consenso En los colectivos de reducida dimensión ello es realmente posible"25. En la familia, por ejemplo, suele darse tal cohesión y en ellas es posible dar rienda suelta a los impulsos altruistas, donde son incluso necesarios. Pero no es posible extrapolar al orden público de las sociedades "extendidas" la armonía y cooperación que reina en las comunidades restringidas. En aquellas "es la renovada competencia y no el consenso lo que aumenta cada vez más la eficacia" 26 . La retórica de la solidaridad altruista que proclama la justicia distributiva "no tiene mérito", porque distribuye lo que no es suyo y proyecta en la esfera pública los valores que imperan en el ámbito privado.

Hayek procura una variante del argumento sobre la dificultad o imposibilidad de organizar la sociedad con vistas a un fin o designio común, llámese "interés público", "bienestar general" o "bien común". Estas expresiones carecerían de un significado suficientemente definido para determinar una vía de acción. Como es imposible abarcar la variedad infinita de necesidades y aspiraciones de las distintas personas, esta imposibilidad crea malestar y tiene una sorpresiva consecuencia práctica. En efecto, si es la autoridad la que debe planificar y jerarquizar las necesidades del colectivo, la insatisfacción termina recayendo sobre ellas y las instituciones: "Los parlamentos comienzan a ser mirados como ineficaces tertulias, incapaces de realizar las tareas para las que fueron convocados. Crece el convencimiento de que, si ha de lograrse una planificación eficaz, la dirección tiene que quedar "fuera de la política" y colocarse en manos de expertos" 27 .

Hayek se considera un "agnóstico" y rechaza el providencialismo de Smith y su idea de la mano invisible. Conserva, sin embargo, su credo, la confianza en una tendencia al equilibrio que cumple las mismas funciones de aquella: suprimir el conflicto, omitir las relaciones de poder, procurar, en suma, una visión risueña, optimista, del funcionamiento del mercado, y suscitar la aceptación de sus disfuncionalidades como males inevitables. "En cada sociedad compleja los resultados de la actuación de cada uno tienen mucho más alcance que su previsión posible, es necesario que el individuo se someta a las fuerzas anónimas y en apariencia irracionales de la sociedad"28. La mano invisible significa, entonces, invisibilidad del todo, imposibilidad de un punto de vista que abarque el conjunto de intereses en juego. En otras palabras: aceptación ciega del libre funcionamiento del mercado, renuncia a la pretensión de conocer lo que es bueno para todos. Hayek denuncia el universal ideológico de la razón de Estado que pretende, al revés del automatismo del mercado, realizar 'el bien común' prescindiendo del egoísmo de los individuos. Es una ilusión pensar que un mejor ordenamiento social "sería posible si adoptáramos a nivel individual actitudes más 'altruistas" 29. El altruismo se da en sociedades arcaicas en las que la colaboración y la solidaridad

Hayek, La fatal..., op. cit., p. 52.

Hayek, Individualism and Economic Order. The Chicago University Press, Chicago, 1948.

Citado en Vergara p. 188.

Hayek, La fatal..., op. cit., p. 52.

Hayek, La fatal..., op. cit., p. 42.

Hume, Tratado, 1739/1886, II, 235; citado en La fatal arrogancia, op. cit., p. 37. 
son indispensables a la supervivencia individual. No es el caso en las sociedades de mercado desarrollado, y Hayek agrega con ironía, que el altruismo es una herencia atávica, una supervivencia de formas de vida arcaicas. "EI primitivo individualismo descrito por Thomas Hobbes no pasa de ser un mito. Nada de individualista tiene el salvaje: su instinto es y será siempre gregario. Nunca se dio en nuestro planeta esa supuesta "guerra de todos contra todos" ${ }^{30}$. Hayek pretende ceñirse a la historia recurriendo a Hume: "Mi exposición, escribe, puede arrancar del aserto de David Hume según el cual 'las normas morales no derivan de la razón" "31. Y en una vena similar, se pregunta: “¿No son valores morales todas las cosas que cada vez con más frecuencia enseñamos a considerar como 'ilusiones del siglo XIX?': libertad, independencia, paz y democracia y respeto por el individuo. ¿Cuáles son los polos fijos que hoy se miran como sacrosantos ?"32. Este argumento es similar al que Marx aduce contra el socialismo utópico: no es la "alienación" ni los valores morales los que determinan el cambio social sino 'contradicciones' del propio orden existente, cuyo desarrollo da origen a un nuevo orden que "supera" dichas contradicciones. El carácter de este proceso sería "histórico-natural", en tanto implica una transformación independiente de la voluntad humana, similar al que se da en la naturaleza; al menos, relativamente independiente, aunque tampoco es azarosa ni a ciegas, porque "resuelve" las contradicciones. Los hombres actúan como "parteras" de la historia, y ésta sigue una racionalidad distinta a los ideales morales de los sujetos individuales. Hayek, por su parte, sostiene que no es posible imponer ideales a la sociedad; existen, sí, dinámicas internas que configuran paulatinamente las leyes e instituciones, análogamente a como se impone un hábito, una costumbre o el lenguaje, independientemente de una voluntad consciente. Hayek llega a descalificar el "mito" de la justicia social, como fruto de la raciocinación y del deseo: una modificación integral de las reglas no puede resultar solo de la acción deliberada. Lo que llama "racionalismo constructivista" es la pretensión de que las instituciones y la misma moral sean resultado de planes, de decisiones intencionales. "Surgen, según él, de un proceso evolutivo inconsciente de auto organización de una estructura" ${ }^{33}$. La transformación de la sociedad no se realizaría constructivamente, como es el caso de los productos fabriles. Una máquina, un artefacto, un invento, por regla, resultan de la creatividad de un inventor. Pero el ordenamiento social no responde a esa lógica, no es resultado solo de la aplicación de un plan elaborado por un sujeto. Descartes pretendía que una ciudad diseñada por un solo urbanista -o un sistema jurídico ideado por un solo sabio legislador-, puede ser más perfecta que una formada a través del tiempo y fruto de muchos autores. "No hay tanta perfección en las obras hechas por varios maestros, como en aquellas en que uno solo ha trabajado. Sí vemos que los edificios que un solo arquitecto ha comenzado y rematado suelen ser más hermosos y mejor ordenados que aquellos otros que varios han tratado de componer". Esta regla sería 
igualmente válida en el orden público: "Esos pueblos que fueron antaño medio salvajes y han ido civilizándose poco a poco, haciendo sus leyes conforme les iba obligando la incomodidad de los crímenes y peleas, no pueden estar tan bien constituidos como los que, desde que se juntaron, han venido observando las constituciones de algún prudente legislador" ${ }^{34}$. Frente a eso, Hayek invoca el testimonio de Cicerón, quien afirmaba la superioridad de la constitución romana, porque "se basaba en el genio de muchos hombres, y no en el de uno solo; no se instituyó en una generación, sino durante un período de varios siglos y muchas generaciones de hombres" ${ }^{35}$. Pretender que sea directamente la razón humana individual la creadora del orden de la sociedad, sostiene, es un mito, una "fatal arrogancia". "Lejos de ser fruto de designio o intención, deriva de la incidencia de ciertos procesos de carácter espontáneo" que dieron lugar a la formación de hábitos o costumbres, cuya práctica "fue generalizándose a través de procesos evolutivos basados en la selección" ${ }^{36}$. Este proceso mostró su eficacia facilitando el crecimiento demográfico y elevando el bienestar material de aquellas poblaciones que aceptaron dichas conductas.

La razón, por tanto, sería producida históricamente, a través de un proceso evolutivo no solo biológico sino de corrección y perfeccionamiento de las instituciones y las leyes. "El hombre devino inteligente porque dispuso previamente de ciertas tradiciones a las que pudo ajustar su conducta" ${ }^{37}$. Sobreestiman el poder de la razón quienes pretenden que es ella la que guía y decide acerca del orden del mundo; la mente humana, contrariamente a lo que piensan los racionalistas, no es productora sino más bien producida, como resultado del ordenamiento social. La pretensión de crear el orden social de acuerdo a exigencias de la razón semeja la arrogancia de una voluntad que quiere suplantar al Dios creador. Las normas y las instituciones económicas se forman y perfeccionan, al igual que las normas morales y el lenguaje mismo, en conformidad con una tradición y según su utilidad social. Las prácticas comerciales y las relaciones de producción traducen dichas normas, es decir: éstas se encarnan y realizan en aquellas y no resultan solo de ideas forjadas por la inteligencia humana. La conexión de esta crítica con la crítica "materialista" de Marx a Hegel es evidente: no son las ideas las que determinan la historia sino la "maduración de contradicciones" inherentes a cada régimen social. Se trataría de una dialéctica anónima, un "proceso sin sujeto" (Althusser), aunque sean los hombres -en plural- sus agentes conscientes.

El "individualismo" de Hayek está en consonancia con esta concepción de la racionalidad. Vergara escribe al respecto: "En su opinión, la característica principal del verdadero individualismo es ser 'primordialmente una teoría de la sociedad, un intento por conocer las fuerzas que determinan la vida social del hombre"” (Hayek, "Individualismo. El verdadero y el falso", Estudios Públicos $\left.N^{\circ} 22\right)$. Esta aclaración

36 Hayek, La fatal..., op. cit., p. 33.

37 Hayek, La fatal..., op. cit., p. 42. 
busca disolver el malentendido que afirma la existencia de "individuos aislados y autónomos, en lugar de entender que el carácter y la naturaleza de los hombres están determinados por su existencia en la sociedad" 38 , aunque la sociedad misma no tiene existencia independiente de los individuos que la integran. "En todas las propuestas de corte colectivista subyace esa atávica añoranza por las formas de vida del 'buen salvaje" $" 39$.

Esta concepción de la realidad humana, según la cual lo realmente existente son los sujetos individuales, parece acorde con la moral vigente en las sociedades "extendidas", y es sinérgico con el funcionamiento del mercado: se aproxima a los criterios que guían a los sujetos económicos. Productores y consumidores se conducen generalmente siguiendo el acicate del lucro y la adaptación a una lucha por "la supervivencia de los más eficaces en el aspecto reproductivo" 40 . El mecanismo del mercado supone una antropología de este tipo y, a la vez, produce y desarrolla el individualismo, la libertad y la responsabilidad, que es, precisamente, lo que requiere la producción y reproducción de la riqueza. El argumento de Rousseau contra "el hombre natural" de Hobbes, en el sentido de que representa solo una proyección del hombre creado por la sociedad del siglo XVIII, y la crítica de Marx a las "robinsonadas" y al homo oeconomicus de la economía clásica son formalmente consistentes, pero chocan contra el hecho de que el sistema produce sus propias criaturas y las crea a su medida. El capitalismo de los siglos XIX y XX no hizo más que reforzar esas tendencias que los clásicos estimaron "naturales", propias de un "estado de naturaleza".

La subjetivación o individuación suele estimarse equivalente a la modernización. Según Hayek, representa un progreso con respecto a los impulsos altruistas y gregarios, en tanto facilitan un mayor desarrollo de la libertad o menores restricciones a la misma. La creatividad, la capacidad de innovación son funcionales al mercado y van de la mano con la mayor individuación. El funcionamiento del sistema de mercado se facilita porque está en concordancia con las tendencias egoístas, incluso con la maldad y falibilidad humanas, agregaría Hayek, que la tradición cristiana reconoce en la idea de "pecado original" 41 . No se necesita, pues, recurrir a un ideal de hombre o atribuir a los existentes virtudes distintas a las que ahora poseen o asignarles tareas diferentes a las que ya cumplen, con vistas a realizar un orden social más perfecto.

Con todo, subsiste la pregunta acerca de si la dupla egoísmo/altruismo es suficiente, y si permite dar cuenta de las relaciones de colaboración y antagonismo social. Pues las conductas individuales -altruistas o egoístas- son en alguna medida, resultado de

38 Hayek, "Individualismo. El verdadero y el falso", Estudios Públicos $\mathrm{N}^{\circ} 22$. Citado por Vergara pp. 63-64.

39 Hayek, La fatal ..., op. cit., p. 51.

$40 \quad$ Hayek, La fatal..., op. cit., p. 62.

${ }_{41}$ Hayek, La fatal arrogancia, op. cit., p. 100. El cristianismo supone un hombre originalmente bueno e inocente, que cae en el mal desde un estado inicial de gracia. La maldad no es el estado original. 
las relaciones sociales y no necesariamente -o no siempre-, causa de las mismas. Los hombres se hallan ligados por lazos de pertenencia -familiares, de clase, nacionales $\mathrm{u}$ otros- que les inducen a obrar de consuno y ocuparse de los asuntos de interés común; privados de esos lazos, en efecto, tienden a conducirse como robinsones egoístas. El sistema económico, y también el sistema político, permiten y aun favorecen cierto tipo de conductas. Un régimen de libertades públicas puede sacar a los individuos de su aislamiento; en cambio, un régimen que suprime las libertades tiende a incomunicarlos y a confinarlos en la privacidad. Hayek restringe la idea de libertad a la autonomía de los individuos para elegir en el mercado. La libertad política, en particular la libertad de expresión, pasa casi desapercibida. Como señala Vergara, él "ha centrado gran parte de su discurso en la crítica del Estado de bienestar y en la idealización de las funciones del mercado" 42 . No pasa de ser un slogan su reiterada afirmación: "la libertad económica es condición de la libertad política". En condiciones de normalidad, sí, pero ha sido precisamente la destrucción de la libertad política la que ha hecho posible la aplicación de estrategias de choque, que en condiciones de normalidad institucional habrían sido impracticables. De hecho, los golpes de mercado siguieron a los golpes de Estado, y el triunfo del neoliberalismo fue sobre todo ideológico y requirió de la previa destrucción de todas las libertades, salvo la económica.

En estrecha relación con el papel suplementario de la razón, Hayek reafirma, siguiendo en esto a Kant, los límites de la razón: solo podemos aspirar a una visión parcial y fragmentaria del mundo, la totalidad no es accesible al conocimiento humano. La pretensión de la metafísica especulativa de alcanzar un saber absoluto de las esencias debe reconocer la irremediable parcialidad de nuestra comprensión del mundo. La imposibilidad de redefinir el todo significa, al mismo tiempo, que un mundo de recambio no cabe en la mente humana, y no sería posible conceptualizarlo sino, a lo más, imaginarlo. Nuestras ideas están, por lo demás, informadas y permeadas por creencias, de modo que no es posible la plena "objetividad". "Una palabra o una frase, un crimen o un castigo no son, desde luego, hechos objetivos en el sentido que se puedan definir sin tener en cuenta nuestro conocimiento de las intenciones conscientes de la gente respecto a ellos"43.

Esto plantea un problema adicional, y es la incidencia de los fenómenos sicológicos en la comprensión de los fenómenos sociales, en particular de las creencias y, por extensión, de las ideologías. Hayek admite el papel constituyente de las creencias cuando afirma: "Las relaciones entre los hombres no pueden definirse en los términos objetivos de las ciencias físicas, sino solo en función de las creencias humanas" ${ }^{44}$. Si las creencias son fenómenos mentales, no susceptibles de definir "en los términos de las ciencias físicas", ¿en qué términos debieran definirse? Hayek, aparentemente, prescinde de la idea de inconsciente y de su aneja: la noción de síntoma. Por lo menos, evita la

42 Vergara, Mercado..., op. cit., p. 236.

43 Hayek, La contrarrevolución en la ciencia, Unión Editorial, Madrid, 2003, p. 56.

44

Hayek, La contrarrevolución..., op. cit., p. 57. 
idea de inconsciente; la reivindica indirectamente cuando se trata de la aceptación de las reglas y normas sociales: "Una saludable inconsciencia de las formas de conducta socializada a la que nos hallamos sujetos es tan necesaria a la sociedad como la ignorancia del trabajo de las vísceras para la salud del cuerpo" 45 .

Es plausible compartir con Kant y con Wittgenstein, la idea de la imposibilidad de acceder al conocimiento de la totalidad, y concordar asimismo con Hume, en la tarea de "cercenar las pretensiones de la razón mediante el análisis racional" 46 . Hayek no "propugna una abdicación de la razón, sino un examen racional del campo donde la razón se controla apropiadamente" ${ }^{47}$. Se trata de una definición estratégica de los límites, porque si las creencias humanas son constituyentes del mundo, como piensa Hayek, ¿por qué detenerse ante la posibilidad de conocerlas y saber cómo surgen y operan sobre la conciencia? ¿Sería recomendable una "saludable inconsciencia” ya que no serían "controlables apropiadamente"?

Hayek admite que la idea del socialismo en todas sus formas y variantes, incluido el liberalismo intervencionista, expresa anhelos, demandas imposibles, al menos inaccesibles a la razón humana. A pesar de reconocer que nunca se ha realizado plenamente el ideal del mercado libre, lo exime de esa crítica, porque supone en él una tendencia espontánea al equilibrio, que el mercado realizaría en virtud de dispositivos de retroalimentación. Las economías dirigidas carecen de correctivos semejantes y los sustituyen con el arbitrio de una autoridad. El régimen de mercado de las "sociedades extendidas" no habría resultado de un intento de ordenar la sociedad conforme a un plan racional, sino de una "evolución cultural basada más en la imitación que en la intuición y la razón”48. ¿Eso excluiría toda intervención reformadora como fruto de una racionalización abusiva? Si la respuesta es afirmativa y la intervención es una deriva totalitaria, un "camino de servidumbre", el neoliberalismo de Hayek sería una ontología del mercado, una "utopía", diría Vergara. Hayek se desmarca de esta crítica al enfatizar la competencia sobre el laissez faire. Las ideologías universalistas que dominaron a mediados del siglo XX intentaban una transformación del mundo, eran “constructivistas", diría Hayek. Pero el neoliberalismo que conocemos está lejos de ser una transformación espontánea o "natural" de las sociedades donde se impuso, como él supone.

¿Qué es, entonces, lo central en este discurso? El análisis del "constructivismo" es una crítica del concepto ilustrado de la razón y de la idea del sujeto moderno; al mismo tiempo, representa una crítica "materialista" del humanismo, que no ignora la lógica económica. La concepción de la competencia, en cambio, reitera en lo fundamental, aunque con otro lenguaje, aspectos previamente enunciados por los clásicos. Desde

45 En Hayek, Los fundamentos de la libertad, Unión Editorial, Madrid, 1988, p. 98, citando a Edward Sapir (Yo destaco).

46 Hayek, Los fundamentos..., op. cit., p. 104.

47 Hayek, Los fundamentos..., op. cit., p. 104.

48 Hayek, La fatal..., op. cit., p. 54. 
luego, la idea del automatismo, que supone condiciones ideales de funcionamiento de los mercados. En lugar de restablecerse el equilibrio, prevalecen las tendencias que "racionalizan" el mercado, sea ajustándolo a la regla de la ganancia o a la creación de hegemonía.

Se ha planteado un problema hasta cierto punto equivalente, a propósito de Marx. Si el "núcleo racional" de su pensamiento se encuentra en El capital y la dialéctica del "modo de producción", se trataría propiamente de una teoría, una "nueva ciencia" de la historia (Althusser). Si, por el contrario, lo definitorio fuera la cuestión de la "alienación" y el establecimiento de una sociedad "reconciliada" -o la realización del comunismo-, se trataría de una ideología o, aun, de una "utopía". Pero el comunismo, desde cierto ángulo, representa la inversión y negación de la lógica mercantil. Una utopía invertida ¿no sigue siendo utopía? Pese a que el neoliberalismo desde hace un tiempo va en inexorable retirada, la simetría con el marxismo indica, desde otro ángulo, la capacidad de supervivencia de las ideologías, aunque ya no ocupen el lugar central.

\section{Referencias bibliográficas}

Adorno, Theodor y Max Horckheimer (2005), Dialéctica de la Ilustración. Madrid: Trotta.

Descartes, Renato, Discurso del método

Góngora, Mario (1981), Ensayo sobre la noción de Estado en Chile en los siglos XIX y XX. Santiago: Editorial Universitaria, 2003.

Hayek, Friedrich (1991), La fatal arrogancia. Santiago: Centro de Estudios Públicos. (1985), Camino de servidumbre. Madrid: Alianza Editorial.

(1988), Los fundamentos de la libertad. Madrid: Unión Editorial. (2003), La contrarrevolución en la ciencia. Madrid: Unión Editorial. “Individualismo. El verdadero y el falso" Estudios Públicos N²2. (1948), Individualism and Economic Order. Chicago: The Chicago University Press.

Hume (1739/1886), Tratado...

Kant (1991), Antropología en sentido pragmático. Madrid: Alianza.

Marx, Karl, El capital. Crítica de la economía política.

Tesis sobre Feuerbach

Mises, Ludwig von (1985), Liberalism. New York: Irvington.

Nietzsche (1947), La voluntad de poder. Buenos Aires: Poseidón.

Vergara, Jorge (2015), Mercado y sociedad. La utopía politica de Friedrich Hayek. Bogotá: CLACSO-Universidad de Chile, Universidad Uniminuto. 